\title{
FRANCIS PONGE E A FIGURAÇÃO DO EU
}

\section{FRANCIS PONGE AND THE SELF-FIGURATION}

\author{
Danielle Grace de Almeida \\ Universidade Federal do Rio de Janeiro \\ Rio de Janeiro, Rio de Janeiro, Brasil
}

\begin{abstract}
Resumo: Em um primeiro momento, o artigo pretende investigar de que modo a experiência com as coisas se impõe como método de construção poética na obra de Francis Ponge. Em seguida, trata-se de analisar os rastros deixados por esse método de escrita que dizem respeito à questão das fronteiras entre o eu e o outro. Para alguns críticos da poesia francesa, na busca de uma linguagem objetiva e impessoal, o poeta moderno acabaria por revelar um sujeito lírico em vias de novos contornos. Para entender essa perspectiva, seguiremos principalmente as reflexões de Michel Collot e Jean-Michel Maulpoix, confrontando-as com a escrita materialista de Ponge, no poema "O caderno de bosque de pinheiros", que compõe a coletânea $A$ raiva da expressão, publicado em 1952.

Palavras-chave: Francis Ponge; Poesia francesa moderna; Sujeito lírico
\end{abstract}

\begin{abstract}
At first, the article intends to investigate how the experience with the things imposes like method of poetic construction in the work of Francis Ponge. Next, it is a question of analyzing the traces left by this method of writing which concern the question of the boundaries between self and other. For some critics of French poetry, in the search for an impersonal and objective language, the modern poet would eventually reveal a lyrical subject in new contours. To understand this perspective, we will mainly follow the reflections of Michel Collot and Jean-Michel Maulpoix, confronting them with the materialistic writing of Ponge, in the poem "O caderno de bosque de pinheiros", that composes the collection A raiva de expressão, published in 1952.
\end{abstract}

Keywords: Francis Ponge; Modern French poetry; Lyrical subject 
Em 1967, em uma série de entrevista a Philippe Sollers para o Office de Radio-Télévision Française, Francis Ponge explica como costumava ser seu método de escrita desde os anos 1930: "No muro tinha pendurado um alfabeto em grandes caracteres; e embaixo da mesa, havia meu Littré $^{l}$. Assim eu trabalhava preparando minha bomba" (Ponge, 1970, 66) ${ }^{2}$. Chegar às coisas, deixá-las surgir das palavras e tomar seu ponto de vista disponibilizando todos os recursos linguístico são iniciativas que ocupam o centro da poética do escritor. Um método explosivo - se quisermos recuperar seu modo de definir a própria obra como bombas - erguendo-se ao mesmo tempo como atividade de "restauração", ou poderíamos dizer de "ressurreição" do homem pela linguagem.

Em La Rage de l'expression [A raiva da expressão], podemos identificar essa atmosfera de "destruição" da linguagem poética e da forma do poema, contribuindo para uma espécie de renascimento de novas expressões. É claro que, ao colocarmos as coisas nesses termos - destruição, restauração, ressurreição -, estamos seguindo os indícios do próprio poeta, para quem os contornos identitários do homem moderno também não podem ser definidos senão por meio de um mecanismo de demolição e ressurgimento para e pela linguagem.

Quando no ardente verão de 1940, caminhando há pelo menos um mês ${ }^{3}$ pelas estradas francesas, Ponge se depara com um bosque de pinheiros, algo similar a uma ressurreição ocorre. Pode-se imaginar o deleite desse encontro tal como seria o de um oásis para um viajante no deserto. A palavra ressurreição, atrelada a esse momento da vida do poeta, evoca seu sentido conotativo, que se exprime como novo ânimo, novas forças. Todavia, ao relacioná-la à poética pongiana, sinto-me autorizada a recuperar sobretudo seu sentido mais restrito: o que alude à ideia de nova existência, de um retorno à vida. No poema "Le Carnet de bois de pins" [O caderno de bosque de pinheiros], que compõe o livro citado acima, temos a sensação dessas acepções compondo um ambiente típico da escrita materialista de Ponge:

Avança-se facilmente (entre seus grandes troncos cuja aparência fica entre o bronze e a borracha). Eles estão bem desimpedidos. De todos os galhos baixos. Não há anarquia, amontoamento de trepadeiras, de atravanco. Pode-se sentar, se estirar à vontade. Neles, há um tapete estendido por todos os lados. Escassos rochedos os mobilham, flores muito baixas. Lá impera uma atmosfera considerada saudável, um perfume discreto e de bom gosto, uma musicalidade vibrante, mas suave e agradável.

Esses grandes mastros violetas, ainda em suas gangues de líquenes e de cascas lascadas, escamosas.

Seus galhos se depelam e seus troncos se descascam.

(Ponge, 1999, 377)

\footnotetext{
${ }^{1}$ Dicionário da língua francesa.

${ }^{2}$ Todas as traduções dos textos em francês são de minha autoria.

${ }^{3}$ Trata-se da debandada de junho de 1940 intitulada "êxodo francês". Nessa ocasião estima-se que pelo menos dois milhões de parisienses peregrinaram pelas estradas em direção ao sul e ao oeste fugindo dos bombardeios da guerra.
} 
Este trecho, intitulado "O prazer dos bosques de pinheiro", ilustra perfeitamente o universo poético que o poeta cria a partir do interesse pela coisa. No bosque de pinheiros de Ponge, "os galhos baixos" "se depelam" e caem, enquanto outras partes crescem nas instâncias verticais, para o alto. Uma vez sobre a terra, os galhos se estendem, mas não "atravanc[am]" o caminho pois deixam de ser galhos mortos para se transformarem em coisa viva: um "tapete de jade", onde se pode sentar ou passear confortavelmente. Dos cumes das árvores às suas largas extensões de veredas, o bosque de pinheiros é um exemplo "maravilhoso" de "sanatório natural" $(1999,377)$. Para o autor, ele parece revelar um modelo de restauração em que nascimento e morte são percebidos menos como início e fim do que como etapas de um funcionamento a serviço de um recomeçar constante.

A experiência do homem com o mundo exterior na poética pongiana se realiza através da provocação da coisa no exercício da palavra. Por essa razão, Ponge se dispõe a escrever sobre as coisas até poder tomar seu partido: "acho que estou começando a me dar conta do prazer do bosque de pinheiros" $(1999,377)$. Nesse caso, um bosque de pinheiros fala. E há muito a dizer, não somente em relação ao seu sistema vivo, refrescante, restaurador, mas à sua morte, sua potência de registro, seu devir página, a folha (de papel), o carnet de que se serve o poeta. Sendo assim, um bosque apontaria para uma "lição" 4 que o autor vai desvelando no decorrer de seu processo investigativo: ir às coisas implica sair de si, ouvir outros sentidos e transformar essa novidade em reformulações expressivas revigorantes. Uma estrapolação verbal que ultrapassaria igualmente as demarcações de um sujeito convictamente ajustado à língua.

Em "INTRODUCTION AU 'PARTI PRIS DES CHOSES"” ["Introdução ao 'Partido das coisas"'], texto escrito em 1928, Ponge escreve as seguintes palavras: "Por muito tempo me fiz as perguntas mais difíceis. Dedico-me agora às coisas mais simples" (Ponge, 2002, 1032). Por conta dessa dificuldade de se expressar pela língua, o poeta adverte que para conhecê-lo será necessário o respaldo das coisas: "Não me conhecerão, não terão nenhuma ideia sobre mim senão por minha concha, minha morada, minhas coleções; ou melhor, pois são armas, minhas panóplias." (Ponge, 2002, 1033) A preferência de Ponge pelas coisas pauta uma discussão importante a respeito da representação do eu na poesia moderna, pois radicaliza a ideia de uma linguagem que, não servindo mais para individualizar o poeta, acaba por arremessá-lo na opacidade dos objetos. Em Ponge, a linguagem está à serviço do concreto, falar das coisas seria buscar retirálas de sua mudez, do mundo petrificado e inaudível em que foram inseridos. Para isso, o poeta constrói um método que visa trabalhar o aspecto mais objetivo da palavra, abandonando a primeira pessoa do singular para lançar mão da terceira, ou seja, renunciando à busca de uma interioridade para se dirigir ao outro.

Mas pensemos essa "lição" pongiana também por outra via. Solicitar as coisas pressupõe abordar primeiramente o aspecto mais usual e prático da língua,

\footnotetext{
${ }^{4}$ Bernard Beugnot fala de uma lição pongiana vinculando-a à um senso ético da atividade de escrita. Cf. BEUGNOT, 1990, 92.
} 
pois que cada objeto existente nela carrega um nome, ou seja, um fundo de sentido compartilhado social e culturalmente. Ora, escolher dentre mil coisas falar do bosque não implicaria, portanto, um ponto de partida individual já que pressupõe uma conjunção única de experiências e subjetividade? Se considerarmos essa reflexão podemos afirmar que o espaço da escrita poética, no caso de Ponge e mesmo da poesia moderna, funcionaria como um espaço em que os limites entre o eu e o outro estão sempre em vias de novas demarcações, longe, de todo modo, dos contornos de um eu imutável.

No intuito de lançar um outro olhar sobre a questão autoral na poesia, discutida intensamente, aliás, desde a segunda metade do século XX, uma parte da crítica francesa contemporânea se posiciona aparentemente na contramão. Se considerarmos as reflexões de Michel Collot e Jean-Michel Maulpoix, por exemplo, podemos pensar a poesia moderna através de uma perspectiva que põe em questão a possibilidade mesmo de uma linguagem objetiva. Para os críticos, mesmo em se tratando de poetas que trabalham a língua em sua materialidade, é possível identificar os traços de uma subjetividade lírica. No que concerne à poesia pongiana, tais questionamentos se proporiam a examinar até que ponto falar das coisas evidenciaria um desejo de expor a si mesmo em um movimento de aproximação não mais do divino ou do sublime, como pretendiam os poetas românticos, mas de um eu que deixa entrever no incômodo silêncio causado pela balbúrdia das palavras.

Em "D'un lyrisme objectif" ["De um lirismo objetivo"], Collot reposiciona o debate em relação à presença de uma voz subjetiva na obra de Ponge. Para ele, o livro mais conhecido do poeta, Le Parti pris des choses [O Partido das coisas], de 1942, veio contribuir para a "redefinição moderna do lirismo como abertura para uma exterioridade e alteridade". Com isso, o crítico defende um outro lirismo, que denomina "objetivo", destacando a distância deste em relação ao "lirismo romântico", "entendido como expressão de uma subjetividade concebida em termos de interioridade e identidade". (COLLOT, 2001, p. 443-449). Decerto, a diferença não pode deixar de ser assinalada pois enquanto a efusão sentimental no romantismo era vista como a expressão de uma singularidade, na modernidade, a consciência (ou pelo menos uma intuição) do atravessamento da alteridade transformou o eu que fala no poema em um sujeito transpassado por outros.

Em Francis Ponge, entre les mots et les choses [Francis Ponge, entre as palavras e as coisas], Collot assinala que "entre" as palavras e as coisas na obra pongiana, é possível evidenciar os "traços da experiência vivida", testemunhando "por eles mesmos que o debate entre palavras e coisas sempre foi intermediado por um sujeito, que procurava se encontrar nessa relação, ainda que às vezes parecesse se excluir" (COLLOT, 1991, p. 9). Nesta perspectiva, "O caderno de bosque de pinheiros" não se realizaria apenas enquanto matéria linguística na tessitura do poema, mas também como percepção de um sujeito que se inscreve no mundo através de suas experiências pessoais.

Em outro texto ainda, "Le Sujet lyrique hors de soi" ["O Sujeito lírico fora de si"], Collot analisa esses aspectos da modernidade através da referência a Rimbaud e a seu projeto de "poesia objetiva". Em "Lettre à Izambard" [Carta a 
Izambar], dita "Carta do vidente", o eu estaria "definido não mais pela sua identidade mas por sua alteridade" (COLLOT, 2005, p. 118). Nessa atitude de Rimbaud, Collot não veria a ausência de um sujeito que fala através da poesia, mas a impossibilidade de conceber um eu senão na transmutação em outro. Esse movimento confuso de reconhecimento de si na alteridade do mundo ocorreria por meio do "exercício da linguagem". É pela língua, pela materialidade da língua, que o sujeito lírico encontraria a matéria do mundo:

É no ato da enunciação que "Eu é um outro", reduzido a um pronome que o designa sem significá-lo, é deportado da primeira para a terceira pessoa do singular; e é pelo "desregramento de todos os sentidos" que ele "chega ao desconhecido". (COLLOT, 2005, p. 118)

Estamos, portanto, nos termos de Collot, diante de um sujeito lírico cuja voz está atravessada de outros ruídos, de outras vozes, embaçando as marcas do individual, confundindo os últimos contornos de nitidez da "primeira" com a "terceira pessoa do singular". Assim, se de fato existe uma eu lírico na poesia moderna, ele é plural, um retalho de subjetividades, para acrescentar mais uma imagem à frase de Jean-Michel Maulpoix, que conclui, em seu ensaio "La quatrième personne du singulier" ["A quarta pessoa do singular"], que "o sujeito lírico moderno é um homem costurado por vários" $(2005,151)$. Com essa frase, o crítico, que se firmou como um dos protagonistas na cena francesa, no que diz respeito à temática do lirismo na poesia moderna, parece apontar para uma multiplicidade que embasa toda a discussão sobre o sujeito.

De muitas formas, vários poetas franceses modernos insinuaram essa ausência de unidade do sujeito moderno, e Maulpoix (2005) menciona essa consciência por parte de poetas como René Char, Henri Michaux e Paul Valéry. E já conhecemos a descoberta que outros antes destes, seus precursores, fizeram a esse respeito, a exemplo de Baudelaire, em "Les Foules" [As multidões], com a imagem do poeta, que, mergulhado na multidão, "goza de [um] incomparável privilégio": "ele pode a seu modo ser ele mesmo e outro" $(1975,291)$; ou de Rimbaud com sua célebre frase citada há pouco "Eu é um outro" e que, como "outro", justamente, se põe a contemplar "a eclosão de [seu] pensamento: eu a olho, eu a escuto" $(1998,313)$. E como não citar também os que compuseram, junto com este, a lista dos poetas malditos: Tristan Corbière, Stéphane Mallarmé, Marceline Desbordes-Valmore.

Esse eu "costurado por vários" de que fala Maulpoix seria na verdade o produto de um processo de mutilação de sua identidade. A desestabilidade do homem moderno se confirma ao longo do tempo na história, ela é um dos fenômenos resultantes da destituição de antigas crenças que asseguravam uma individualidade íntegra, como a presença do divino ou do amor idealizado. $\mathrm{O}$ crítico mostra em outro livro, Du Lyrisme [Do lirismo] (MAULPOIX, 2000, p. 111-147), que, nesse processo de auto (re)conhecimento, o escritor, "mal agrupado a si", contemplaria sua obra: "esse tipo de tela ou concha que chamamos "texto", e nela encontraria um refúgio onde viria "se alojar". 
Tomando como base as reflexões de Roland Barthes sobre o texto moderno, Maulpoix (2005) segue descrevendo um sujeito que é "engolido por suas obras", e que "dá a esse infinitivo, a esse infinito, a esse indefinido que é a escrita pedaços de si para serem rú́dos, fragmentos de finitudes, de transitório e de contingente". Seria, aliás, a era moderna e tudo o que ela engendra que teriam exposto esse "cerne de indeterminação" do sujeito "esse centro vazio, lugar do chamado, da demanda" $(2005,151-152)$ desvelando ao mesmo tempo o que ele vai designar como o

paradoxo essencial de um sujeito ao mesmo tempo possuído e despossuído. Um sujeito que parece deter seu poder de uma perda. Um sujeito desassujeitado de sua identidade (...) que se torna o lugar de ressonância da alteridade. (...) Como se o "eu" fosse não mais que um porta-voz de uma ausência e de uma pluralidade. (MAULPOIX, 2005, p. 151-152).

Tal perspectiva, no que concerne a essa ideia de um sujeito instável e desalojado de sua "singularidade", encontra-se bem próxima da de Collot (2005). No artigo citado anteriormente, "O sujeito lírico fora de si", o crítico explica que, "não podendo mais cantar Deus ou o Ser ideal através das palavras e das maravilhas da criação", o sujeito descobriria que a "transcendência é apenas a máscara de uma contingência, de uma ilusão lírica", e ele se encontraria então "jogado em um mundo e uma linguagem desencantados". Assim, questiona o crítico, "ceder ao canto e ao êxtase não é se deixar ludibriar pela língua?" (COLLOT, 2005, p. 114-115). A língua se torna o alvo de desconfiança do sujeito moderno. Não tendo, porém, como se libertar dela, iria em sentido contrário, declarando, então, seu "sujeitamento" a ela.

Seguindo a perspectiva apresentada pelos críticos, podemos dizer que estar submetido à língua é estar subjugado ao seu poder, ser apoderado por ela e, assim sendo, o sujeito se sentiria ao mesmo tempo possuído por outro e destituído de si. Seria justamente nesse jogo dinâmico de "possessão" do outro e de "despossessão" (MAULPOIX, 2005) de si que o sujeito moderno se encontraria. Mais importante: desse modo, ele experimentaria a consciência de estar no centro desse movimento, a todo momento lançando-se e sendo lançado para "fora de si" (COLLOT, 2005). Collot reitera, portanto, que "se o sujeito lírico cessa de se pertencer é por que ele experimenta seu pertencimento ao outro, ao mundo, ao tempo, à linguagem. Longe de ser o sujeito soberano da palavra, ele é sujeito a ela

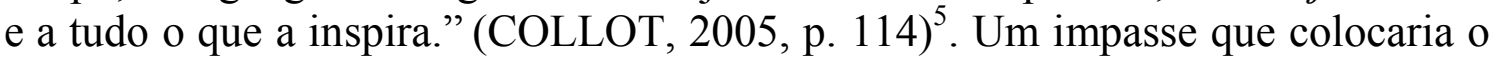
sujeito moderno na experiência da perda, pois, por mais que a língua não sirva para expressá-lo inteiramente, ela permanece seu recurso único: "o sujeito só pode se expressar através dessa carne sutil que é a linguagem, que dá corpo ao seu pensamento, mas que habita um corpo estrangeiro." (COLLOT, 2005, p. 114115)

\footnotetext{
${ }^{5}$ Italico do autor.
} 
Se a questão do sujeito desalojado de si está colocada para Ponge, sua forma de reagir e se expressar seria, como vimos, indo às coisas. Tomando esse recurso como modo particular de entrar na língua pela escrita, o poeta encenaria exemplarmente o confronto do sujeito consciente de sua subserviência em relação à linguagem. Daí a origem de um "drama da expressão" (COLLOT, 2005 e MAULPOIX, 2013), pois perceberia a impossibilidade de se expressar, de "expressar seus sentimentos mais íntimos na linguagem de todo mundo" (COLLOT, 2005, p. 119). Restaria ao poeta, então, fugir desse "carrossel", e, para isso, escolheria “"conhecer milhões de sentimentos' diferentes (...) no contato com as coisas, cuja diversidade infinita nunca foi verdadeiramente considerada pela linguagem. Pois os homens só fizeram projetar sobre elas seu miserável estado de alma" (COLLOT, 2005, p. 120). Tanto Collot quanto Maulpoix apontam para esse "drama" que daria lugar a uma crise levando o poeta a declarar, em "Rhétorique" ["Retórica"], texto escrito entre 1929 e 1930, a impotência diante das palavras "todas prontas". Vejamos o fragmento em que, para os críticos, o poeta exporia paradigmaticamente esse conflito.

Podem lhe dizer: ao menos deem a palavra a menor parte de vocês. Sejam poetas. Eles responderão: mas é sobretudo aí, ainda aí que sinto os outros em mim mesmo, quando procuro me expressar e não consigo. As palavras são todas prontas e se expressam: elas não me expressam. (PONGE, 1999, p. 193)

Se as palavras não servem para a construção de uma identidade plena e insiste em confrontar o poeta a essa dissolução constante que ocorre na modernidade, a atitude encontrada seria a de se lançar em uma construção própria de sentidos recebendo das coisas mais triviais uma retórica única e renovada. Em "Le drame de l'expression" ["O drama da expressão"], Maulpoix lembra que o "partido poético [de Ponge] é inventar uma retórica por objeto ou por poema: encontrar para cada objeto uma forma, um modo de escrever que esteja de acordo com o seu próprio ser" $(2013,169)$. Em outras palavras: a "crise" advinda pela consciência de estar subjugado pelas palavras que "não [o] expressam", conduziria o poeta a prestar uma atenção redobrada às coisas, fazendo-as falar em seu lugar. Nesse sentido, Collot assinala que "de certa maneira, tomar o partido das coisas ainda é 'tomar seu próprio partido'. O sujeito que não pode se expressar busca se escrever através dos objetos que ele descreve 'renunciando a se conhecer de outro modo senão aplicando-se às coisas" (COLLOT, 2005, p. $120)^{7}$.

Nessa dinâmica particular entre linguagem e coisa, caberia então pensar em termos de um lirismo "que não consiste em exprimir os sentimentos interiores,

\footnotetext{
${ }^{6}$ Termo utilizado por Ponge, em Méthodes (1961). O poeta constrói essa imagem para se referir à tendência do homem em se movimentar, tal como o carrossel, em círculo retornando sempre ao mesmo lugar de partida, mas também em torno de si mesmo e de um ideal humanista ultrapassado. Cf. Ponge, 1999, 690.

${ }^{7}$ COLLOT, 2005, p. 120.
} 
mas essa emoção que nasce dos exteriores e que pode tornar-se a fonte de "sentimentos desconhecidos"" (COLLOT, 2005, p. 121). Sentimentos que o poeta encontraria especialmente nas coisas em que o homem se imagina ausente, como o "seixo" que, ao invés de uma mudez absoluta, é eloquente. Ele anunciaria características que dizem respeito ao homem, mas que ele desconhece, "sentimentos particulares" (PONGE, 1999, p. 526), até então desconhecidos do homem, mas que falam profundamente ao/do homem.

Tendo em vista a leitura em relação à questão autoral realizada por Collot e Maulpox, podemos nos perguntar de que modo esse "novo lirismo" poderia empreender um diálogo com a escrita de Ponge e a poética das coisas. Longe de negar a importância dessa perspectiva e de sua acuidade crítica, penso, no entanto, que é preciso refletir quando da tendência a perder de vista um dos traços importantes da poesia moderna. Isto é, a potência criativa que o poeta moderno parece encontrar na dissolução de sua identidade na linguagem de todos.

Sabemos como a queda da auréola para Baudelaire, em "Perte d'auréole" ["Perda da auréola"], representou não somente a perda do prestígio do poeta, mas também a sua liberdade. Com a desobrigação de pertencer a si mesmo e encarnar uma identidade íntegra, intocável, o poeta pôde sair pelas ruas sem ser percebido: "Posso agora passear incógnito", ou mesmo transvertido de outros: "E eis-me aqui semelhante a ti" $(1975,352)$. Em "O caderno de bosque de pinheiros", mais que um eu que procura se encontrar nas coisas, o poeta parece se servir de sua condição de perda de si para radicalizar o apagamento das fronteiras entre o eu e o outro. Consideremos mais um trecho do poema:

Bosque de pinheiros, saia da morte, da não-evidência, da nãoconsciência! (...)

Surja, bosque de pinheiros, surja na palavra. Não conhecem você. - Dê sua fórmula. - não foi por acaso que você foi notado por F. Ponge... (PONGE, 1999, p. 384-385)

Aqui, um vocativo introduz a estrofe convocando a coisa à existência. Trata-se de uma cena de ressureição pela palavra: "saia da morte". Nesse trecho, Ponge encena aquele que possui a palavara soberana e que tira as coisas de sua não-evidência, devolvendo-lhe a vida. A cena nos permite um paralelismo com o episódio da ressurreição de Lázaro em que, segundo o novo testamento, Jesus teria ressuscitado seu amigo apenas chamando-o pelo nome ? ${ }^{9}$ A escrita performática de Ponge nos permite pensar que há ressurreição no momento em que a palavra vem reverter a opacidade das coisas, fazendo-as surgir na consciência do homem enquanto concretude verbal a ser incorporada na língua.

\footnotetext{
8 "Le Galet" [O seixo] é também o título de um poema de Ponge que compõe O Partido das coisas. Cf. PONGE, 1999.

${ }^{9}$ Segundo o Evangelho de João, Jesus ressuscitou Lázaro, sepultado há quatro dias, por meio da palavra: "Jesus clamou alto dizendo: 'Lázaro, sai para fora", depois "Disse-lhes Jesus: 'Desataio e deixai-o ir"” Cf. Bíblia. João 11: 43, 44
} 
Por outro lado, poderíamos analisar esta voz dramática na poesia de Ponge como modo de colocar em cena o processo criativo da escrita poética. Foi também pela palavra, o logos, que Deus deu vida às coisas do mundo chamando cada uma pelo seu nome (Gênesis, cap. 1). No episódio da criação do mundo, a palavra divina não é ressureição, mas o verbo criador. Mesmo nessa chave de compreensão, o poema permanece o resultado de um chamado à vida pela palavra. Cada poema, assim como as coisas, exigiria, então, uma convocação própria, uma língua por poema, a fundação de uma "nova retórica" (Ponge, 1999, $537)^{10}$.

Outro aspecto importante a ser assinalado nesse trecho do poema é o uso da terceira pessoa para se referir à primeira: "não foi por acaso que você foi notado por F. Ponge". Falar na terceira pessoa é uma forma de destruir a possibilidade de falar de si como um eu intacto da presença do outro. Ao mesmo tempo, usar a terceira pessoa enunciando seu próprio nome é abrir a fresta por onde se pode entrever o eu. Em outros termos, pode-se dizer que o que está em questão nesse gesto de Ponge é o paradoxo que há em toda tentativa de expressão. Assim como não é possível falar de si mesmo excluindo a presença do outro, não há terceira pessoa que seja referida sem que arraste consigo, em uma espécie de ausência-presença ${ }^{11}$, a primeira.

À maneira de Ponge, falar das coisas pressupõe uma encenação, que, por sua vez, funda seu método de escrita. A esse respeito, é possível arriscar um diálogo com Georges Bataille (2016) e o conceito de dramatização. Em "Princípios de um método e de uma comunidade", o filósofo explica que dramatizar é um modo de atingir a experiência interior lançando-se, ao mesmo tempo, na experiência com o outro: "Se não soubéssemos dramatizar, não poderíamos sair de nós mesmos, viveríamos isolados e comprimidos." $(2016,42)$. A dramatização, nos termos de Bataille, realiza-se expondo uma tensão, implica entrar na linguagem encenando seu desejo e sua impossibilidade de saída: "dramatizar: é a vontade, que se acrescenta ao discurso, de não se manter no enunciado". Ou seja, "o que conta não é mais o enunciado do vendo, é o vento" $(2016,45)$. A poesia pongiana dramatiza uma escrita que se insere de modo paradoxal na língua. Nesse sentido, ser como deus que enuncia suas palavras e faz surgir a vida é tão ilusório quanto a própria linguagem. Somente dramatizando ressuscitando a impossibilidade do logos - é que se poderia comunicar com o mundo, sem deixar, no entanto, de evidenciar nesse gesto a própria falência.

Sendo a poesia um espaço de embate com a linguagem, ela seria também a prova do fracasso desse empreendimento, pois que todo o esforço de superação da língua se revela, quando muito, em um novo modo de manuseio e de destruição desta. Ou seja, não há saídas nem direção que não exponham a própria falência dessas tentativas. Certamente, a poesia de Ponge performatiza o fracasso da

\footnotetext{
${ }^{10}$ Ver também Ponge, 1999, 192-193.

${ }^{11}$ Jacques Derrida, em Signéponge, realiza uma leitura importante para pensar a questão da assinatura em Ponge. Em um processo de "permanência" e "desaparecimento", que lembra essa ausência-presença, o nome do poeta despontaria em sua escrita como uma marca da presença paradoxal do autor na obra literária moderna. Cf. Derrida, 1984, 57.
} 
linguagem. Não há meios de se livrar da inexpressividade para o homem, a não ser extrapolando todos os limites, inclusive os da fronteira do eu. Ponge parece começar pelo nome das coisas, de onde se vê toda uma coleção de títulos compondo sua obra. Isso seria também um modo de expor os sentidos usados das coisas, usando-os de tal modo que um novo limiar de sentido e de olhar sobre ela se instaure.

Assim como Bataille, é pela escrita que Ponge dramatiza a crise da linguagem, mostrando que a saída, e a "não-saída", só pode se realizar na manipulação da matéria verbal, e de sua experimentação contínua. Tudo isso nos conduz ao modo como a poesia pongiana encena os limites da linguagem como força criativa. Michel Deguy, em La poésie n'est pas seule [A poesia não está só], afirma que "a saída é e não-é a saída", pois que "há somente impasses, ruas, aporias". Sendo assim, poderíamos nos perguntar "qual pode ser então o caminho que é e não é o caminho, qual é a saída se não há saída? A saída, o encaminhar-se para a saída, o caminhar é então o de passar de um impasse a outro" (Deguy, 1988, 169). Seguindo as indicações que Ponge deixa em sua obra, podemos dizer que, assim como Baudelaire, a perda da auréola, por mais drástica que seja, é potência criativa, ela presenteia o poeta com um eu que se dissolve na alteridade e se contempla como um passante incógnito.

\section{Referências}

BAUDELAIRE, Charles. Euvres Complètes I, Bibliothèque de le Pléiade. Paris: Gallimard, 1975.

BATAILLE, Georges. A Experiência interior. Vol.1, Trad. Fernndo Scheibe. Belo Horizonte: Autêntica Editora, 2016.

BEUGNOT, Bernard. Poétique de Francis Ponge. Paris: PUF, 1990.

COLLOT, Michel. Francis Ponge: entre les mots et les choses. Col. Champ Poétique Mayenne: Champ Vallon, 1991.

. D'un lyrisme objectif. In: ROUGET, F.; Stout, J. (org.). Poétijques de l'objet. L'objet dans la poésie française du Moyen Age au XXe siècle. Paris: Honoré Champion, 2001.

. Le sujet lyrique hors de soi. In: RABATE, D. (org.). Figures du sujet lyrique. Paris: Perspective littéraire, Puf, 2005.

DEGUY, Michel. La poésie n'est pas seule. Paris: Seuil, 1987.

DERRIDA, Jacques. Signéponge. Edição bilíngue Francês-Inglês. Nova York: Comlombia University Press, 1984.

MAULPOIX, Jean-Michel. Du Lyrisme. Paris: José Corti, 2000. 
. La Quatrième personne du singulier. In: RABATE, D.; SERMET, J.; Vadé, Y. (org.). Le Sujet lyrique en question. Bordeaux: Presses universitaires de Bordeaux, 2005.

. Par quatre chemins. Paris: Pocket, 2013.

PONGE, Francis. Entretiens de Francis Ponge avec Philippe Sollers. Paris. Gallimard/Seuil. 1970.

Gallimard, 1999. . Euvres Complètes I, Bibliothèque de le Pléiade. Paris:

Gallimard, 2002. . Euvres Complètes II, Bibliothèque de le Pléiade. Paris:

RIMBAUD, Arthur. CEuvres. Paris: Pocket, 1998.

Danielle Grace de Almeida DanielleGrace15@gmail.com

Recebido em: 10 set. 2018 Aceito em: 7 dez. 2018

Publicado em: 29 dez. 2018 